\title{
Small Stirling Technology Exploration Power for Future Space Science Missions
}

\author{
Scott D Wilson \\ NASA Glenn Research Center \\ 21000 Brookpark Rd. \\ Cleveland, OH 44135 \\ 216-433-6681 \\ Scott.D.Wilson@nasa.gov
}

\author{
Nicholas Schifer \\ NASA Glenn Research Center \\ 21000 Brookpark Rd. \\ Cleveland, OH 44135 \\ 216-433-6681 \\ Nicholas.A.Schifer@nasa.gov
}

\author{
Michael R. Casciani \\ Vantage Partners, LLC. \\ 3000 Aerospace Parkway \\ Brook Park, OH 44142 \\ 216-416-5528 \\ Michael.R.Casciani@nasa.gov
}

\begin{abstract}
High efficiency dynamic Radioisotope Power Systems (RPS) could be mission enabling for low power space applications such as small probes, landers rovers, and communication repeaters. These applications would contain science instruments and be distributed across planetary surfaces or near objects of interest where solar flux is insufficient for using solar cells. Small RPS could be used to provide power for sensing radiation, temperature, pressure, seismic activity, and other measurements of interest to planetary scientists. Small RPS would use fractional versions of the General Purpose Heat Source (GPHS) or Light Weight Radioisotope Heater Units (LWRHU), to heat power conversion technologies. Dynamic power systems are capable of three to four times higher conversion efficiency compared to static power conversion technologies, and would provide an equal amount of power using less fuel or more power using an equal amount of fuel. Providing spacecraft with more power could decrease duty cycling of basic functions and, therefore, increase the quality and abundance of science data. NASA Glenn Research Center (GRC) is developing a low power dynamic RPS that would convert heat from multiple LWRHU to one watt of usable direct current electric power for spacecraft instrumentation and communication. The power system could be used to charge batteries or capacitors for higher power burst usage. The initial design, called Small Stirling Technology Exploration Power (smallSTEP), is around $3 \mathrm{~kg}, 11 \mathrm{~cm}$ diameter $X 32 \mathrm{~cm}$ long, and converts 8 watts of heat to one watt of electricity using a Stirling convertor. This low power conversion system represents a new class of RPS with power levels two orders of magnitude lower than prototypes currently being developed for space applications under NASA contracts. Development of the 1-watt RPS includes maturation of convertor and controller designs, performance evaluation of an evacuated metal foil insulation, and development of system interfaces. Initial demonstration of the subsystems has been completed in a laboratory environment and a higher fidelity system is being pursued for demonstration in relevant environments for use on small spacecraft needed to carry out future space science missions.
\end{abstract}

\section{TABLE OF CONTENTS}

1. INTRODUCTION . .1

2. INSULATION AND CONVERTOR TESTING..............2 3. FLEXURE AND CONTROLLER TESTING..................3 4. SUMMARY .............................................................. ACKNOWLEDGEMENTS..............................................4

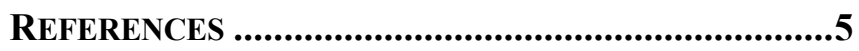

\section{INTRODUCTION}

Low power Radioisotope Power System (RPS) conversion technologies that could convert very small amounts of heat to usable amounts of electric power include static Thermoelectric Couples (TEC) and dynamic Stirling convertors. Of the 51 missions studied by Jet Propulsion Laboratory, Goddard Space Flight Center, and Ames Research Center, 27 used low power systems that produced 5 $\mathrm{mW}$ to $9 \mathrm{~W}$ of electrical power [1]. The mission studies contained science instruments distributed across planetary surfaces or near objects of interest to measure data like wind, temperature, pressure, seismic activity, and other surface measurements for planetary science. These studies used fractional versions of the General Purpose Heat Source (GPHS) or one or more Light Weight Radioisotope Heater Units (LWRHU) as a heat source. Energy storage like batteries and super-capacitors were required for most designs to enable periodic energy intensive functions like data collection, communications, and roving. The report concluded that power requirements increased as the capability of each mission increased. These studies utilized thermoelectric technologies capable of $2-5 \%$ conversion efficiency and were limited to $500 \mathrm{~mW}$ of output power. Small RPS could be used to enable a long-life network of small distributed stations that monitor and transmit science data on lunar or planetary surfaces. To increase the usable output power and decrease the required fuel, high efficiency dynamic RPS are being developed at the NASA GRC. Such technologies could increase science data return on future missions or become mission enabling for low power applications. Initial efforts to develop subassemblies for a low power dynamic RPS have led to a design that would convert heat from multiple LWRHU to 1 watt of usable direct current electric power for spacecraft instrumentation and communication [2].

The 1-Watt RPS is being developed to provide power options for micro spacecraft or communication repeaters. Development efforts include maturation of the major subassemblies that make up the small RPS, including a heat source assembly, free-piston Stirling convertor, electrical controller, and insulation package and associated structure. The design effort has focused on minimization of thermal and electrical losses for the insulation, convertor, and controller while providing a notional heat source assembly design that 
will require further maturation. Figure 1 shows the concept with integrated convertor and heater assembly inside the insulation package. This RPS concept has a mass of under 3 $\mathrm{kg}$ and is roughly $32 \mathrm{~cm}$ long and $11 \mathrm{~cm}$ in diameter. The heat source is mounted inside the insulation package and is radially constrained using point contacts to minimize internal thermal losses. The heat source and Stirling hot end are radiatively coupled using closely spaced non-contacting plates. The Stirling convertor is constrained at the cold end and the heater head is radially constrained using point contacts. This design would avoid mechanical loading of the thin-walled Stirling heater head while still enabling an adequate Stirling hot-end temperature. The heater head wall could be thickened to enable a compressed mechanical load configuration and higher heater head temperatures. The concept keeps the controller warm by encapsulating it inside the housing near the rejection flange, which should offer around 4 watts of waste heat.

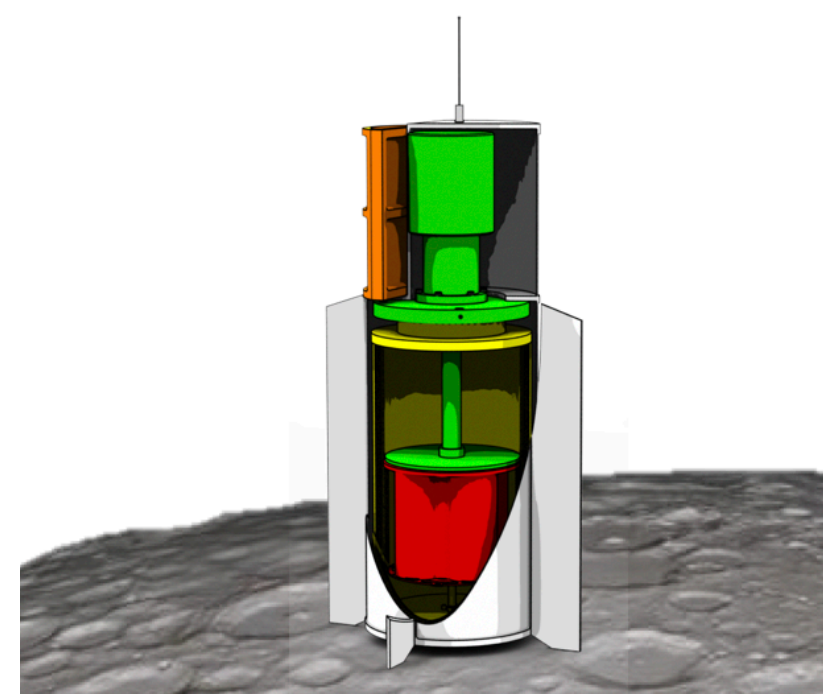

Figure 1. Conceptualization of the small dynamic RPS on the lunar surface.

\section{INSULATION AND CONVERTOR TESTING}

Designed to provide localized heating for spacecraft electronics, hundreds of Light Weight Radioisotope Heater Units (LWRHU) have been used on numerous spacecraft over the past few decades. The units have a thermal output of 1.1 Watts at beginning of life and are $2.6 \mathrm{~cm}$ in diameter and $3.2 \mathrm{~cm}$ in length. While proposed as a means for heat input on power applications, these small heat sources have never actually been used in that manner. This concept would use 8 LWRHUs and would need to prevent helium creation from the decay of the Plutonium fuel from entering the evacuated insulation assembly over the life of the mission. The heat flux coming from the surface of a LWRHU is about $274 \mathrm{~W} / \mathrm{m}^{2}$ while the heat flux from a GPHS is about $11,000 \mathrm{~W} / \mathrm{m}^{2}$. With such little heat available from the LWRHU, a highly effective insulation package is needed in order to achieve the desired hot-end temperatures for the convertor. To achieve the target hot-end temperature of $350^{\circ} \mathrm{C}$, a multi-layer metal insulation (MLMI) design was fabricated by Peregrine Falcon Corporation under contract with GRC. The initial design utilizes metal foils to shield the heat that would be available from eight LWRHUs. Figure 2 shows an image of the MLMI with an electric heat source, a thermal simulator, and fluid heat rejection loop. The figure also shows the delivered configuration that utilizes a large Conflat flange to enable high vacuum levels and disassembly and inspection of the thermal simulator between tests.

The MLMI package utilizes strategically located thin metallic shields to minimize conduction heat loss to the environment. The design is evacuated to eliminate convection heat transfer and minimize parasitic conduction losses at internal interfaces. The thermal simulator contains an insertion rod that is instrumented with thermocouples to enable calculation of heat transfer through the assembly. Such data will be used to validate thermal models and verify the performance of the insulation package. A fluid heat exchanger is included to remove heat at the cold end of the assembly. This assembly should be adequate for testing in air or vacuum. Nuclear fuel is not allowed for laboratory testing so electric resistance cartridge heaters are being used to enable demonstration and performance testing. The LWRHU electric simulator utilizes four vacuum rated cartridge heaters to simulate the 8 watts thermal input anticipated from the LWRHUs.

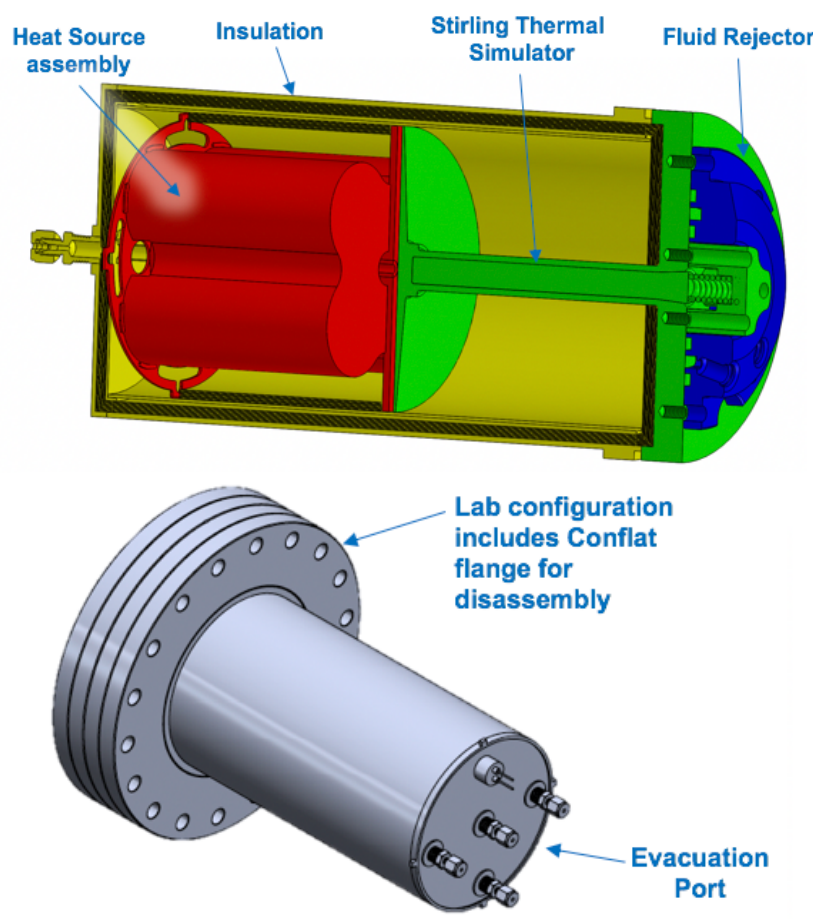

Figure 2. Multi-Layer Metal Insulation Functional Demonstration Hardware, including the electric heat source, Stirling thermal simulator, and fluid rejector.

Proof-of-concept hardware has been designed for easy assembly in a laboratory environment and has been prepared to support initial testing. A split-Stirling configuration was 
selected among a field of options and utilizes a gap regenerator, which is basically a two-walled foil regenerator and does not contain any engineered microstructures. Table 1 shows the engine and alternator design parameters, including a mean charge pressure of 7.5 bar and hot-end temperature of $350{ }^{\circ} \mathrm{C}$, both of which are considered to be relatively low compared to higher power designs for space. The hot-end temperature was selected to minimize insulation losses and heat source surface temperature. The Stirling cycle utilizes an operating frequency of $100 \mathrm{~Hz}$ and displacer and piston amplitudes of $2 \mathrm{~mm}$ and $4 \mathrm{~mm}$, respectively. The convertor utilizes an alternator with a solid core material and button style magnet, making the design simple to assemble and robust to overstroke events. The alternator also used flexure bearings to maintain the radial running clearances that are required for long life wear-free operation. The flexures were designed to withstand around $19 \mathrm{~g}$ of constant lateral loading. Constant lateral or axial loads could be applied temporarily during propulsion maneuvers or atmospheric planetary body entry, decent, and landing events. Additional analysis is planned to estimate how much constant loading could be experienced without axial collisions of moving parts.

Table 1. Stirling Convertor Design Parameters

\begin{tabular}{|l|c|}
\hline \multicolumn{1}{|c|}{ Parameter } & Goal (CBE) \\
\hline \hline${\text { Electrical output, } \mathrm{W}_{\mathrm{e}}}$ & $1.0(1.2)$ \\
${\text { Thermal input, } \mathrm{W}_{\text {th }}}$ & $6.5(6.8)$ \\
Convertor efficiency, $\%^{\circ}$ & $20(21)$ \\
Alternator efficiency, $\%$ & $85(85)$ \\
Acceptor temperature, ${ }^{\circ} \mathrm{C}$ & $350(350)$ \\
Rejector temperature, ${ }^{\circ} \mathrm{C}$ & $<50$ \\
Operating frequency, $\mathrm{Hz}$ & 100 \\
Mean pressure, $\mathrm{MPa}$ & 7.6 \\
Pressure amplitude, $\mathrm{MPa}$ & 0.9 \\
Displacer amplitude, $\mathrm{mm}$ & 2.0 \\
Piston amplitude, $\mathrm{mm}$ & 4.0 \\
\hline
\end{tabular}

Figure 3 shows the laboratory design used to perform a proof of concept of the very low power machine. This version does not emphasize small size or low mass but does enable a wide variety of instrumentation for parameter measurement and bolted flanges for ease of disassembly and inspection. These features would not necessarily be present in flight designs. A thick-wall gas duct was used in place of a small diameter gas line to enable testing of two different alternator designs with bolted configurations. Internal position sensors were included for the displacer and piston position, which will enable measurement of the amplitudes and the phase angle between the moving components and alternator current. A pressure transducer was also included for measurement of the compression-space dynamic pressure amplitude. All of these measurements will enable characterization of the thermodynamically-dynamically couple machine. Future versions will minimize mass, size, and sensors.

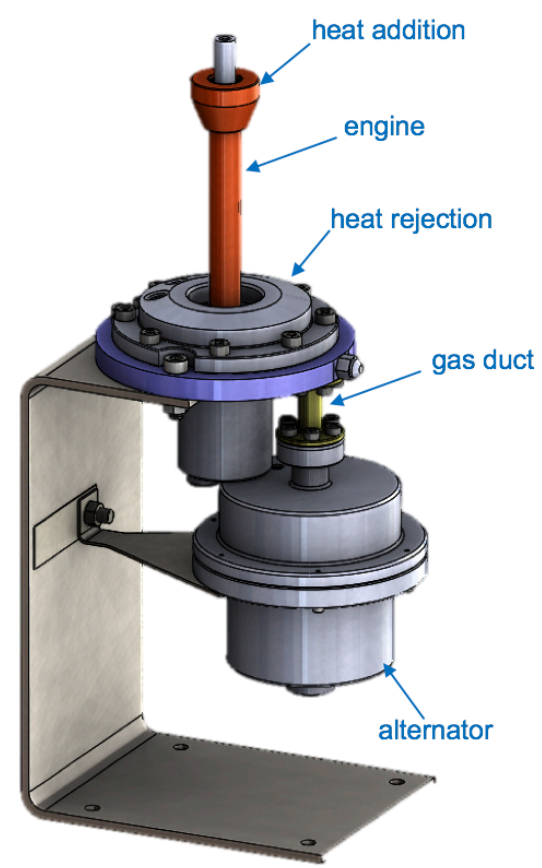

Figure 3. Stirling convertor test setup.

\section{FleXure AND ConTroller Testing}

A flexure test rig was assembled to enable fatigue testing of flexures at the design frequency through a range of amplitudes that exceed the design amplitude. The displacer and piston flexures were designed with a sufficiently high stress margin and fabricated using chemical etching.

Stress testing of those flexure designs was used to characterize operating amplitude for a number of cycles prior to failure. Finite element analysis was used to predict static stress for a given deflection and the corresponding stress was noted for each amplitude tested. Those results were used to develop a relationship for fatigue stress vs. number of cycles to failure, or S-N curve. The piston flexures require an amplitude of over $7 \mathrm{~mm}$ to reach values expected to fail and the available drive motor could only be used up to $6 \mathrm{~mm}$ so the $\mathrm{S}-\mathrm{N}$ curve could only be created for the displacer flexure, shown in Figure 4. The displacer flexures were tested at amplitudes that exceeded the $3.0 \mathrm{~mm}$ hard stop limit, from $3.4 \mathrm{~mm}$ to $5 \mathrm{~mm}$. Those values correspond to 1.7 to 2.5 times higher than the $2.0 \mathrm{~mm}$ nominal amplitude. During fatigue testing, two materials were used, including 1095 carbon spring steel and Sandvik 7c27mo2. The first flexures fabricated used 1095 carbon spring steel because it was readily available compared to the Sandvik material. The 1095 spring steel has a better endurance fatigue limit of 1,000 MPa but has relatively poor corrosion resistance while the Sandvik material has a lower but sufficient endurance limit of 710 $\mathrm{MPa}$ and much better corrosion resistance. The Sandvik material was selected for use in the convertor but shakedown testing of the flexure and clamp design used 1095 spring steel. Both flexure designs easily exceeded 10 million cycles operating at $100 \mathrm{~Hz}$ (1.2 days), the high end of a typical range 
used as the threshold for identifying transition from high cycle fatigue, or the finite-life regime, to the infinite life regime. The boundary between the finite-life and infinite-life regimes, or endurance limit, lies somewhere between 1 million and 10 million cycles for steels. The 1095 spring steel and Sandvik displacer flexures have been demonstrated up to 700 million cycles (81 days) and 200 million cycles (23 days), respectively, at 1.7 times higher than the nominal amplitude without fracture. Similarly, the 1095 spring steel and Sandvik piston flexures have been demonstrated up to 500 million cycles (58 days) and 100 million cycles (12 days), respectively, at 1.2 times higher than the nominal amplitude without fracture. These initial tests included realistic clamping configurations and provided confidence that research testing would not be hampered by spring failures. Extended duration testing of piston and displacer flexures is planned once designs have been finalized.

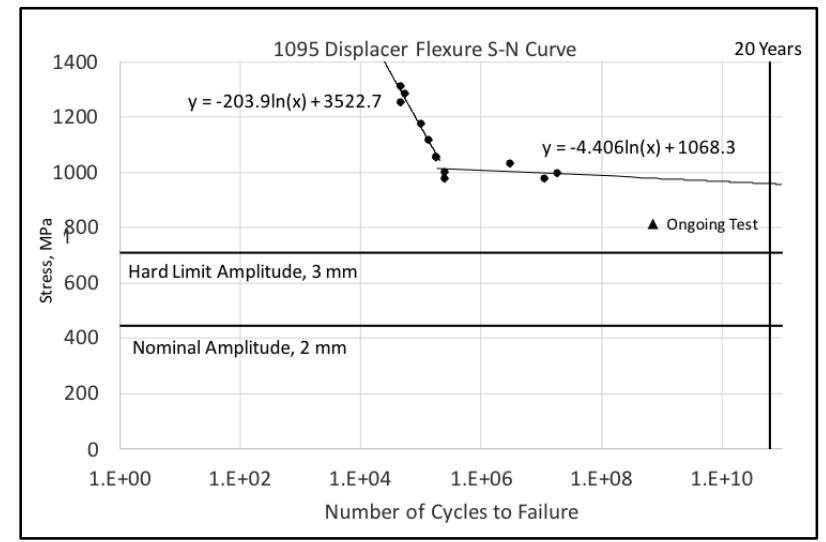

Figure 4. Displacer Flexure Test Data (1095 only).

The free-piston Stirling convertor needs a controller that can maintain stability and rectify the power. With the desire to arrive at a simplistic controller design that can be further matured to flight, an analog controller was designed and has been tested at NASA GRC. The design is intended to control convertor dynamics and convert alternator $\mathrm{AC}$ voltage to $\mathrm{DC}$ for a spacecraft bus or energy storage system. The basic requirements are to provide load control, convert the alternating current available from the linear alternator to direct current, and shunt excess power when the energy storage is full. The analog controller was modeled in LTspice using a linearized version of the alternator. A MOSFET Hbridge architecture was used to rectify the $\mathrm{AC}$ voltage from the alternator to DC voltage. The load voltage control circuit contains a DC capacitor and provides a DC voltage to the loads. It also includes a synthetic capacitor to decrease Total Harmonic Distortion (THD) and improve efficiency. As an option to improve controller efficiency, a waveform smoothing circuit was included to successfully lower the THD to acceptable levels while maintaining the desired power output of $1 \mathrm{We}$ output. Breadboard testing was performed to validate models and enable selection of an optimal design. Representative test data is shown in Figure 5 and Table 2 summarizes the test results. The ideal diode rectifier design achieved an efficiency of $80 \%$ while the improved version used wave form smoothing to achieve an efficiency of $91 \%$.

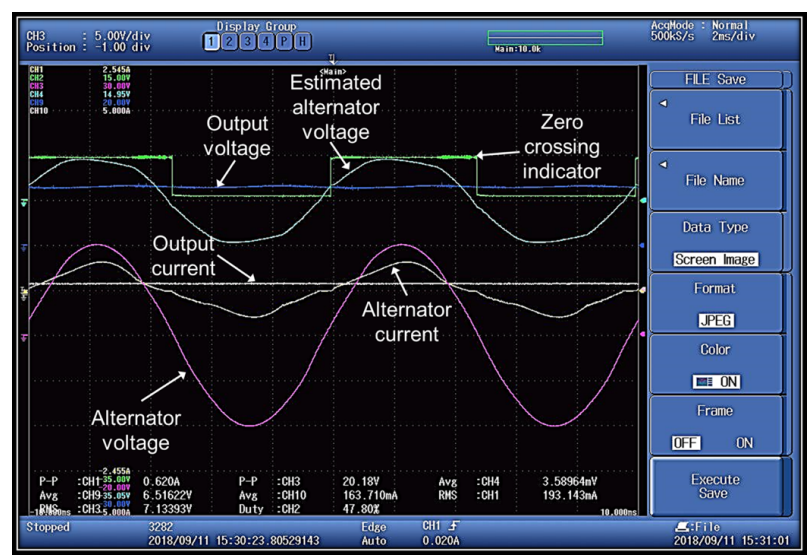

Figure 5. Breadboard controller test data.

Table 2. Controller Breadboard Testing Results

\begin{tabular}{|c|c|c|}
\hline Value & $\begin{array}{c}\text { Ideal diode } \\
\text { rectifier }\end{array}$ & $\begin{array}{c}\text { Wave Form } \\
\text { Smoothing }\end{array}$ \\
\hline \hline Alternator Voltage, $\mathrm{V}_{\mathrm{p}-\mathrm{p}}$ & 25.3 & 25.4 \\
Alternator Power, $\mathrm{W}_{\mathrm{e}}$ & 1.37 & 1.34 \\
Controller voltage, $\mathrm{V}_{\mathrm{dc}}$ & 11.7 & 11.5 \\
Controller Power, $\mathrm{W}_{\mathrm{e}}$ & 1.11 & 1.22 \\
Controller efficiency & $80 \%$ & $91 \%$ \\
\hline
\end{tabular}

\section{SUMMARY}

High efficiency dynamic RPS could be used to increase science data return on future missions or could be mission enabling for low power applications. NASA GRC is developing a low power dynamic RPS design that would convert heat from multiple light weight radioisotope heater units to 1 watt of usable direct current electric power for spacecraft instrumentation and communication. The power system could be used to charge batteries or capacitors for higher power burst usage. A low power free-piston Stirling convertor and controller are being fabricated by GRC for initial demonstration and a facility test station with data systems has been prepared. Development also includes maturation of a highly efficient multi-layer metal insulation package. Proof-of-concept hardware is being prepared to demonstrate this new class of power conversion device in a laboratory environment. This power system could be matured for small probes, landers, rovers and communication repeaters needed on future space exploration missions.

\section{ACKNOWLEDGEMENTS}

This work is funded through the NASA Science Mission Directorate and the Radioisotope Power Systems Program Office. The authors would like to thank the RPS Program and SmallSTEP team members. Any opinions, findings, conclusions, or recommendations expressed in this article are those of the authors and do not necessarily reflect the views of NASA. 


\section{REFERENCES}

[1] NASA Office of Space Science, "Enabling Exploration with Small Radioisotope Power Systems", JPL Pub 04-10, September 2004.

[2] Wilson, S.D., Geng, S.M., Penswick, L.B., Schmitz, P.C., "Radioisotope Heater Unit-Based Stirling Power Convertor Development at NASA Glenn Research Center", NASA/TM-2018-219704.

\section{Biography}

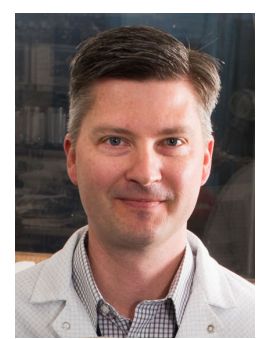

Scott Wilson received an M.S. in Mechanical Engineering from Cleveland State University in 2011. He has been performing tests and analysis of Stirling power convertors for more than 15 years and currently serves as the Dynamic Power Conversion Technical Lead for the Thermal Energy Conversion Branch at NASA Glenn Research Center. His career started with CFD analysis of reciprocating engine flow physics and testing free-piston Stirling convertors for $S R G-110$. He was responsible for performance and efficiency calculations of convertors operating in the Stirling Research Laboratory (SRL) and currently manages contracts in support of the Dynamic Radioisotope Power Systems (DRPS) Project.

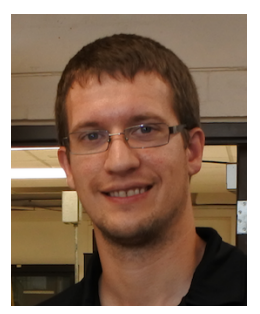

Nicholas Schifer received a B.S. in Mechanical Engineering from Ohio Northern University in 2009. He joined the Thermal Energy Conversion Branch at the NASA Glenn Research Center in 2009 and has supported development of free-piston Stirling convertors for space applications. He currently serves as cognizant engineer in the Stirling Research Laboratory (SRL) supporting performance and robustness testing to mature dynamic power conversion technologies for space.

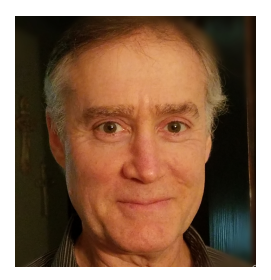

Michael Casciani received a B.S. in Electrical Engineering from the State University of New York at Buffalo in 1989 and an M.S. in Electrical Engineering from Cleveland State University in 1993. He has worked at the NASA Glenn Research Center since 1990 as a contractor supporting various space flight projects. Michael has supported the Stirling Research Lab providing test support and Stirling engine controller development since 2016. 